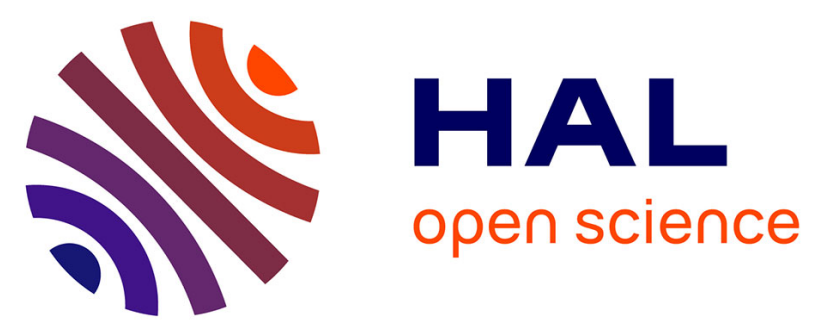

\title{
Complexes of humic acid with cationic surfactants support the supramolecular view of extracted humic matter
}

Abdul Amir Chaaban, Bruno Lartiges, Eliane El Hayek, Veronique Kazpard, Celia Plisson-Chastang, Patricia Vicendo, Celine Caillet

\section{To cite this version:}

Abdul Amir Chaaban, Bruno Lartiges, Eliane El Hayek, Veronique Kazpard, Celia Plisson-Chastang, et al. Complexes of humic acid with cationic surfactants support the supramolecular view of extracted humic matter. Environmental Chemistry, 2021, 18 (4), pp.156-167. 10.1071/EN21031. hal-03320901

\section{HAL Id: hal-03320901 https://hal.science/hal-03320901}

Submitted on 16 Aug 2021

HAL is a multi-disciplinary open access archive for the deposit and dissemination of scientific research documents, whether they are published or not. The documents may come from teaching and research institutions in France or abroad, or from public or private research centers.
L'archive ouverte pluridisciplinaire HAL, est destinée au dépôt et à la diffusion de documents scientifiques de niveau recherche, publiés ou non, émanant des établissements d'enseignement et de recherche français ou étrangers, des laboratoires publics ou privés. 


\section{Complexes of humic acid with cationic surfactants support the supramolecular view of extracted humic matter}

${ }^{1}$ University of Toulouse III (Paul Sabatier), Geosciences Environnement Toulouse (UMR CNRS-UPS-IRD), 14 Av. E. Belin, 31400 Toulouse, France.

${ }^{2}$ Lebanese University, Faculty of Sciences, Plateform for Research and Analysis in Environmental Science, EDST, Campus Hadath, Lebanon.

${ }^{3}$ University of Toulouse III (Paul Sabatier), Laboratoire de Biologie Moléculaire Eucaryote Centre de Biologie Intégrative, 31400 Toulouse, France.

${ }^{4}$ University of Toulouse III (Paul Sabatier), Laboratoire des Interactions Moléculaires et Réactivités Chimiques et Photochimiques (UMR CNRS-UPS 5623), 31400 Toulouse, France.

${ }^{5}$ Université de Lorraine, CNRS, LIEC, F-54000 Nancy, France.

a Present address: Departement of Pharmaceutical Sciences, MSC09 5360, University of New Mexico, College of Pharmacy, Albuquerque, New Mexico, 87131, United States

*Corresponding author: Bruno LARTIGES

E-mail: bruno.lartiges@get.omp.eu 


\section{Abstract}

35 The structural organization of extracted humic matter, polymeric or supramolecular, has been 36 a long-standing controversial issue. In this paper, we show that the interaction between a 37 reference humic material, the Suwannee River Humic Acid (SRHA), and a homologous series 38 of cationic surfactants (n-alkyl trimethyl ammonium chloride) provides key insights to resolve 39 the controversy. By combining measurements of turbidity, electrophoretic mobility, surface 40 tension, and cryogenic transmission electron microscopy, we show that (i) the binding of 41 cationic surfactant to the anionic humic acid is initially triggered by electrostatic interactions;

42 (ii) the contrasting evolution of turbidity-surfactant concentration curves implies that the 43 surfactant alkyl chain interacts with the hydrophobic moieties of humic matter from very low concentrations of surfactant; (iii) a drastic restructuring of humic matter occurs upon surfactant binding, which brings out supplementary anionic humic sites; (iv) in the presence of C12 cationic surfactant, SRHA spontaneously forms stable nanoscale unilamellar vesicles, which,

47 in addition to the high surface activity of complexes, could be of interest in the remediation of oil-contaminated environments; (v) the sequence of molecular structures obtained from SRHA with increasing amounts of C12-cationic surfactant - humic-rich vesicles, aggregates, surfactant-rich vesicles - bears striking similarities with the phase behaviour of aqueous mixtures of anionic and cationic surfactants, thus supporting the supramolecular view of humic structure.

54 Keywords: Suwannee River Humic Acid, cationic surfactant, DTAC, CTAC,

55 Supramolecular organization, Cryo-transmission electron microscopy 


\section{Introduction}

58 Humic substances are traditionally extracted by alkali from natural organic matter (NOM)

59 present in soils, sediments and natural waters, and are then further classified into humic acid 60 and fulvic acid according to their solubility in water (Thurman and Malcolm 1981). Whether 61 those operationally defined substances represent a native state of NOM has been a legitimate and recurrent debate in the literature (Burdon 2001; Kelleher and Simpson 2006; Lehman and Kleber 2015; Baveye and Wander 2019; Olk et al. 2019). Another controversial issue, also related to the nature of NOM, concerns the organization of extracted matter. Humic substances are generally regarded as macromolecular structures resulting either from the polymerisation of phenolic/peptidic/carbohydrate compounds (Stevenson 1994; Swift 1999; Gerke 2018) or from the abiotic and/or biotic degradation of original pre-existing biopolymers (Hayes et al. 1989; Burdon 2001). They have also been described as micelle-like or pseudomicelles aggregates (Wershaw 1999; von Wandruszka 2000), and more recently as supramolecular assemblies of small heterogeneous molecules essentially associated through hydrogen bonds and hydrophobic interactions (Piccolo 2001; Simpson et al. 2002, Sutton and Sposito 2005).

The argumentation for a macromolecular humic structure is based on the fact that the humic matter retains its structural integrity through the extensive fractionation procedures that precede reliable molecular weight assessments (Swift 1999; Cameron et al. 1972). On the other hand, experimental support for a supramolecular structure essentially relies on the disaggregation of humic matter detected after the addition of organic acids to disrupt the hydrogen bonds that hold the humic components within molecular aggregates (Piccolo and

78 Conte 1999; Piccolo 2001; Simpson et al. 2002; Smejkalova and Piccolo 2008). The enhanced solubilisation of non-polar organic compounds in the presence of humic substances, 
the humic matter and NOM (Carter and Suffet 1982; Engebretson and von Wandruszka 1997; von Wandruszka, 2000; Chilom and Rice 2009; Chilom et al. 2013). However, such hydrophobic domains may be accounted for either by the occurrence of micellar aggregates or by the formation of hydrophobic cores upon polymer coiling. Likewise, aggregation studies of extracted humic matter and NOM do not directly identify a macromolecular or supramolecular structure (Kerner et al. 2003; Chilom et al. 2009; Wells and Stretz 2019).

Chaaban et al. (2016) recently proposed to probe the organization of extracted humic matter through its interaction with varying concentrations of a cationic surfactant. In the case of macromolecules, the association with the oppositely charged surfactant leads to the formation of complexes that start to aggregate at a Critical Aggregation Concentration (CAC) in surfactant (Fig. 1a). Above CAC, further addition of surfactant proceeds through cooperative binding of supplementary molecules to the complexes that progressively become decorated with micelle-like structures of surfactant (Jain et al. 2004; Bain et al. 2010; Khan and Brettmann 2019). Eventually, the polyelectrolyte/surfactant complexes re-solubilize. The CAC in macromolecule-surfactant suspensions generally occurs several orders of magnitude lower than the Critical Micellar Concentration (CMC), i.e. the concentration at which free surfactant molecules associate with each other to form micelles (Khan and Brettmann 2019). In the case of a supramolecular assembly of small heterogeneous molecules, the interaction with the cationic surfactant may organize new types of self-assemblies such as mixed micelles, vesicles, or lamellae (Fig. 1d), thus achieving much richer phase behaviour than what would be observed with macromolecules (Marques et al. 1998; Marques et al. 1999). The occurrence of a given self-assembly can reasonably be predicted from the geometrical characteristics of individual components according to the molecular packing concept introduced by Israelachvili et al. (1976) (Fig. 1b-c-e). In the case of an association between a cationic surfactant and anionic 
molecules which leads to more complicated expressions for the packing parameter (Manohar 107 and Narayanan 2012). Applying the above approach to the Suwannee River fulvic acid 108 (SRFA), Chaaban et al. (2016) showed that the addition of increasing amounts of Dodecyl109 trimethylammonium chloride (DTAC) successively leads to fulvic acid-rich unilamellar vesicles, aggregates, DTAC-rich unilamellar vesicles, and mixed micelles. Such a sequence, consistent with a supramolecular organization of fulvic matter also suggests that a major component of SRFA has an overall molecular size similar to that of DTAC.

113 This paper extends the previous research by investigating the complexation behaviour of 114 Suwannee River humic acid (SRHA), a reference aquatic humic matter of the International 115 Humic Substances Society (IHSS), in the presence of a series of alkyltrimethylammonium 116 chloride cationic surfactants $\left(\mathrm{C}_{8} \mathrm{H}_{17} \mathrm{~N}^{+}\left(\mathrm{CH}_{3}\right)_{3} \mathrm{Cl}^{-}(\mathrm{OTAC}), \mathrm{C}_{12} \mathrm{H}_{25} \mathrm{~N}^{+}\left(\mathrm{CH}_{3}\right)_{3} \mathrm{Cl}^{-}\right.$(DTAC), $\left.117 \mathrm{C}_{16} \mathrm{H}_{33} \mathrm{~N}^{+}\left(\mathrm{CH}_{3}\right)_{3} \mathrm{Cl}^{-}(\mathrm{CTAC})\right)$. Turbidity, surface tension, and electrophoretic mobility measurements are combined with cryogenic transmission electron microscopy observations to examine the characteristics of complexes formed between SRHA and the homologous series of surfactants under conditions of concentration relevant to natural aquatic systems. The

121 formation of oppositely charged humic-rich and surfactant-rich vesicles supports a 122 supramolecular organization for SRHA.

\section{Experimental}


2.1 Materials. Suwannee River Humic acid (SRHA) was purchased from the International Humic Substances Society (IHSS) (Humic Acid Standard 2S101H). The isolation procedure of SRHA includes (i) filtration of the river water through a $0.45 \mu \mathrm{m}$ porous membrane filter, (ii) addition of concentrated $\mathrm{HCl}$ to lower the $\mathrm{pH}$ of the filtrate to 2.0, (iii) $\mathrm{XAD}-8$ resin adsorption and then elution with $0.1 \mathrm{M} \mathrm{NaOH}$ followed by immediate acidification of eluate with $\mathrm{HCl}$ to avoid oxidation of the humic matter, (iv) centrifugation, washing with water, and freeze-drying to obtain SRHA in a solid form (Thurman and Malcolm 1981). According to Thurman and Malcom (1981), the recovery factor is better than $95 \%$ for humic substances from the Suwannee River.

The cationic surfactants - Dodecyltrimethyl ammonium chloride $\left(\mathrm{C}_{12} \mathrm{H}_{25} \mathrm{~N}^{+}\left(\mathrm{CH}_{3}\right)_{3} \mathrm{Cl}^{-}-\mathrm{DTAC}\right.$ $\geq 99 \%$, Octyltrimethyl ammonium chloride $\left(\mathrm{C}_{8} \mathrm{H}_{17} \mathrm{~N}^{+}\left(\mathrm{CH}_{3}\right)_{3} \mathrm{Cl}^{-}-\right.$OTAC $\left.\geq 97 \%\right)$ and Cetyltrimethyl ammonium chloride $\left(\mathrm{C}_{16} \mathrm{H}_{33} \mathrm{~N}^{+}\left(\mathrm{CH}_{3}\right)_{3} \mathrm{Cl}^{-}-\mathrm{CTAC} \geq 98 \%\right)$ - were purchased from Sigma-Aldrich. The surfactants were used without further purification. Those compounds are quaternary ammonium salts: they completely dissociate in water and possess a permanent positive charge. According to literature data, DTAC is readily soluble in water at room temperature with a CMC of $21.7 \mathrm{mmol} / / \mathrm{L}$ at $30^{\circ} \mathrm{C}$ (Perger and Bester-Rogac 2007) and a Krafft temperature below $0^{\circ} \mathrm{C}$ (Lachewsky et al. 2005) - the Krafft temperature of a surfactant is the minimum temperature that ensures the flexibility of the alkyl chain and the formation of micelles. The CTAC Krafft temperature is about $18^{\circ} \mathrm{C}$ with a $\mathrm{CMC}$ of $1.3 \mathrm{mmol} / \mathrm{L}$ at $30^{\circ} \mathrm{C}$ (Tan et al. 2010); finally, OTAC possesses a CMC of $250 \mathrm{mmol} / \mathrm{L}$ at $28^{\circ} \mathrm{C}$ with a $\mathrm{Krafft}$ temperature below $0^{\circ} \mathrm{C}$ (Lindblom and Lindman 1973). As the determination of the Critical Micelle Concentration is very sensitive to both the presence of impurities and the method of measurement, the CMCs of commercial surfactants were measured using a Wilhelmy plate (KRUSS K12 Processor Tensiometer). As shown in Figure S1 of Supporting Information, CMCs of $20 \mathrm{mmol} / \mathrm{L}, 1.1 \mathrm{mmol} / \mathrm{L}$, and $200 \mathrm{mmol} / \mathrm{L}$ were then obtained for DTAC, CTAC, and 
OTAC, respectively. The presence of a minimum in the surface tension curve of DTAC indicates a slight contamination by a non-ionic impurity. In that case, the re-increase in the surface tension vs concentration curve marks the $\mathrm{CMC}$, the surface-active impurities leaving the air/water interface as they incorporate the forming DTAC micelles (Martinez-Balbuena et al. 2017). Our experimentally determined values of CMC are used throughout the paper.

2.2 Sample preparation. As this work was initially inspired by the literature on ternary diagrams of oppositely charged surfactants, which are generally conducted in pure water, all the solutions were prepared without any supporting electrolyte. The DTAC and CTAC stock solutions were prepared in deionised water (Millipore, MilliQ, resistivity $>18.2 \mathrm{M} \Omega . \mathrm{cm}$ ) at 10 $\mathrm{g} / \mathrm{L}$ and $200 \mathrm{mg} / \mathrm{L}$, respectively. For OTAC, stock solutions at 10, 35 and $70 \mathrm{~g} / \mathrm{L}$ were necessary to minimize the aliquot volume of surfactant solution added to the SRHA suspension. The concentration of the SRHA suspension was adapted to the technique of investigation used. For turbidity, surface tension and electrophoretic mobility measurements, a SRHA suspension of $20 \mathrm{mg} / \mathrm{L}$, i.e. $\sim 12 \mathrm{mg} \mathrm{C} / \mathrm{L}$, was prepared by adding the appropriate mass of humic acid into $500 \mathrm{ml}$ of deionised water. For Cryogenic Transmission Electron Microscopy (Cryo-TEM), a stock solution of $1 \mathrm{~g} / \mathrm{L}$ was used. The SRHA stock solutions were stirred overnight and then vacuum-filtered through a $0.2 \mu \mathrm{m}$ cellulose acetate membrane (Macherey-Nagel). Fresh SRHA suspensions were prepared every day and the dissolved organic carbon of each stock suspension was checked (Shimadzu TOC-Vcsn). An average value of $12.28 \pm 1.53 \mathrm{mg} \mathrm{C} / \mathrm{L}$ was obtained for the $20 \mathrm{mg} / \mathrm{L}$ suspensions. The suspensions with too much or too little DOC were discarded.

The SRHA/Surfactants complexes were prepared by adding aliquots of the concentrated surfactant solutions to a total of $10 \mathrm{~mL}$ (1 mL for Cryo-TEM) of SRHA suspension. The SRHA/surfactant suspension was gently shaken (3 times) and then placed in a thermostated bath at $30^{\circ} \mathrm{C}$. The humic acid suspension and the surfactants stock solutions were also 
maintained at $30^{\circ} \mathrm{C}$ during the experiments. Such temperature was selected to be above the

178

Krafft temperature of all surfactants used in the study. The experiments were carried out at $\mathrm{pH}$ 4.5 (equilibrium $\mathrm{pH}$ of the SRHA stock suspension at a $20 \mathrm{mg} / \mathrm{L}$ concentration in pure water) and at $\mathrm{pH}$ 6.7. In the latter case, the $\mathrm{pH}$ of the SRHA stock suspension was adjusted by dropwise addition of $\mathrm{NaOH} 0.1 \mathrm{M}$ (about $250 \mu \mathrm{L}$ in $0.5 \mathrm{~L}$ stock suspension of SRHA). The $\mathrm{pH}$ of SRHA/surfactant mixtures was not readjusted after surfactant addition. The $\mathrm{pH}$ was nevertheless measured in the $10 \mathrm{~mL}$ vial at the end of the experiment (Fig. S3).

2.3 Characterization of SRHA/Surfactants complexes. The turbidity of SRHA/Surfactants suspensions was measured as a function of time using a HACH LANGE 2100Q turbidimeter. The conductivity and the $\mathrm{pH}$ (WTW Multiline F/SET), the surface tension (KRUSS K12 Processor Tensiometer using a Wihelmy plate), and the electrophoretic mobility of the complexes (Malvern Zetasizer Nano ZS) were measured after 1h of mixing.

The cryo-TEM observations were carried out at the Multiscale Electron Imaging (METI) platform (University of Toulouse III (Paul Sabatier)) using a JEOL 2100 Lab6 transmission electron microscope equipped with a Gatan 626 electron microscope cryo-holder. The samples were prepared by depositing $4 \mu \mathrm{l}$ of SRHA/Surfactant suspension onto a LACEY/CARBON FILM grid previously ionized using PELCO-easiGlow 91000 glow discharging-cleaning system. After blotting for $0.2-0.8$ seconds (depending on the surfactant concentration) with filter paper to remove the excess liquid (using a Leica EM GP controlled vitrification system, chamber at $30{ }^{\circ} \mathrm{C}$ and $85 \%$ relative humidity to avoid evaporation of the liquid), the grid was immediately plunged into liquid ethane close to its freezing point $-183^{\circ} \mathrm{C}$. The vitrified sample was then transferred to the microscope under liquid nitrogen to prevent any sample perturbation and the formation of ice crystals. The images were then recorded with a Gatan ultrascan1000 and Gatan ultrascan4000 camera under low dose conditions ( $\sim 10-20$ electrons per $\left.\AA^{2}\right)$. 


\section{RESULTS}

203

3.1 Turbidity measurements. Figure 2 compares the turbidity curves obtained $1 \mathrm{~h}$ after mixing a suspension of $20 \mathrm{mg} / \mathrm{L}$ SRHA with various amounts of surfactants. After $1 \mathrm{~h}$, the turbidity measurements, if not stable, vary less than $10 \%$ over the following hour (see Figure S2 in Supporting Information). The result of the interaction between SRHA and the homologous series of cationic surfactants is represented as a function of the surfactant concentration normalized to their respective critical micelle concentration (CMC) to account differences in water solubility of the surfactants (Cases and Villieras 1992).

Drastic differences are observed in the turbidity curves according to the alkyl chain length of the surfactant: OTAC addition to SRHA leads to a minor increase in turbidity even at high surfactant concentration. In contrast, the addition of DTAC to SRHA suspensions is characterized by a strong initial increase in turbidity that broadly peaks around $0.28 \mathrm{CMC}_{\mathrm{DTAC}}$ ( $5.6 \mathrm{mmol} / \mathrm{L})$, followed by a gradual decrease to reach low turbidity values at high surfactant concentrations. The addition of DTAC to pure water leads to a negligible increase in turbidity (fig. 2a). The SRHA/CTAC turbidity curve exhibits two very noisy peaks at roughly 0.09 and $0.18 \mathrm{CMC}_{\mathrm{CTAC}}($ i.e. 0.1 and $0.19 \mathrm{mmol} / \mathrm{L}$ ); the noisy pattern mainly results from the presence of clearly visible but sparse aggregates in suspension. At pH 6.7 (Figure 2b), the interaction between SRHA and DTAC leads to two prominent turbidity peaks around 0.15 and 0.45 $\mathrm{CMC}_{\mathrm{DTAC}}($ i.e. 3 and $9 \mathrm{mmol} / \mathrm{L}$ ). In the low concentration range, the base of the first turbidity peak exhibits smaller turbidity values than at $\mathrm{pH}$ 4.5. This can be explained by the higher negative charge of SRHA at pH 6.7 (Lead et al. 2000; Hosse and Wilkinson 2001), which requires higher DTAC concentrations to start forming aggregates. 
The formation of two turbidity peaks for the associations SRHA/CTAC at $\mathrm{pH} 4.5$ and

SRHA/DTAC at $\mathrm{pH}$ 6.7, as well as the limited interaction between SRHA and OTAC at natural $\mathrm{pH}$, reveal complex interactions between the humic acid and the cationic surfactants. Those interactions certainly involve the charge neutralization of SRHA anionic groups by the positive head groups of surfactants but also various hydrophobic effects driven by the alkyl chain length of surfactants. All the surfactants used in this study are 1:1 salts. However, as illustrated in Figure 2 from additions of various $\mathrm{NaCl}$ concentrations to the humic suspension, the change in solution ionic strength brought by the surfactant does not play any significant role in determining the turbidity of the suspension in the range of surfactant concentrations investigated. Moreover, the $\mathrm{pH}$ of the SRHA/surfactants suspensions remains close to the initial pH (Figure S3 in Supporting Information).

3.2 Electrophoretic mobility measurements. The electrophoretic mobility of SRHA/Surfactant complexes exhibits two different patterns as a function of surfactant concentration (Figure 3). For SRHA/DTAC complexes at both $\mathrm{pH} 4.5$ and 6.7 , the electrophoretic mobility increases rapidly at low surfactant additions, and then more slowly at higher DTAC concentrations. Interestingly, the point of zero mobility $(\mathrm{PZM})$ reached at about $3.2 \mathrm{mmol} / \mathrm{L}$ and $5.5 \mathrm{mmol} / \mathrm{L}$ for $\mathrm{pHs} 4.5$ and 6.7 , respectively, cannot be related to the turbidity peaks: indeed, the PZM occurs before the turbidity peak at $\mathrm{pH} 4.5$, and is situated in the valley between the two turbidity peaks at pH 6.7 (Figure 3b).

In contrast, for OTAC and CTAC, the electrophoretic mobility becomes more negative at low surfactant concentration, reaches a minimum at about $0.01 \mathrm{CMC}$ for both surfactants, and then increases to reach positive values from $0.06 \mathrm{CMC}_{\mathrm{CTAC}}$ in the case of $\mathrm{CTAC}$, or decreases to stabilize at negative values in the case of OTAC. Unlike DTAC, the point of zero mobility of SRHA/CTAC complexes can be related to the first turbidity peak. It is worth noting that the initial electrophoretic mobility of SRHA colloids could not be measured with the Nanosizer 
and that all the data points reported in the plots identify SRHA/surfactant complexes. Previous capillary electrophoresis measurements carried out by Hosse and Wilkinson (2001) led to electrophoretic mobilities of SRHA close to -3.8 and to $-4.910^{8} \mathrm{~m}^{2} \mathrm{~V}^{-1} \mathrm{~s}^{-1}$ at $\mathrm{pH} 4.5$ and 6.7 , respectively. This suggests that the electrophoretic mobility of OTAC/SRHA and CTAC/SRHA complexes comprises an initial maximum not resolved with our measuring technique.

3.3 Surface tension measurements. Figure 4 shows the surface tension of SRHA/surfactant suspensions as a function of surfactant concentration or surfactant concentration normalized to the corresponding CMC in a semi-log plot. The surface tension of pure surfactant solutions is also shown for comparison. Two main regimes can be distinguished: at very low surfactant concentration, i.e. [surfactant] $/ \mathrm{CMC}<0.1$, the surface tension of SRHA/surfactant system decreases more rapidly with concentration than that of pure surfactant. Such synergistic effect is attributed to the strong electrostatic interaction between the humic anionic groups and the cationic headgroups of surfactant that leads to humic/surfactant complexes of enhanced hydrophobicity (Gamboa and Olea 2006). Following this decrease, the surface tension curve stabilizes or even exhibits a well-defined breakpoint in the case of CTAC. Upon further addition of surfactant, the surface tension of SRHA/surfactant system remains fairly constant, before decreasing again at higher surfactant concentration. Such additional drop in surface tension suggests the presence of non-associated surfactant in addition to the SRHA/surfactant complexes. It can also be noted that, in that concentration range ([surfactant]/CMC $\geq 0.1)$, the longer the alkyl chain, the higher the surface activity of SRHA/surfactant complexes. At high surfactant concentration, the surface tension of pure surfactant solutions becomes lower than that of SRHA/surfactant systems. 
and 7 , respectively. At the concentration of the DTAC stock solution $(38 \mathrm{mmol} / \mathrm{L})$, i.e. slightly above the CMC, micelles could not be clearly seen in the micrographs (Fig. 5a). In contrast, humic structures in the 3-5 $\mathrm{nm}$ range and small linear aggregates of those structures, 30 to 140 $\mathrm{nm}$ in length, are found for a SRHA concentration of $1 \mathrm{~g} / \mathrm{L}$ and an equilibrium $\mathrm{pH}$ equal to 3.1 (Fig. 5b). Such observations are consistent with previous fluorescence correlation spectroscopy measurements that suggest a partial aggregation of SRHA at low $\mathrm{pH}$ (Hosse and Wilkinson 2001; Duval et al. 2005). However, the linear aspect of aggregates likely results from the intense shearing that occurs during the blotting stage while draining the excess liquid deposited on the grid (Lee et al. 2012).

Addition of a $7.610^{-3} \mathrm{mmol} / \mathrm{L}$ DTAC concentration to the $1 \mathrm{~g} / \mathrm{L}$ SRHA suspension leads to the formation of slightly irregular globules, about $25-50 \mathrm{~nm}$ in diameter, marginally aggregated, and with no internal structure (Fig. 5c2). Such globules may represent the early stages of interaction between DTAC molecules and SRHA and might be attributed to mixed micelles. The same amount of surfactant diluted in deionised water leads to featureless micrographs (Fig. $5 \mathrm{c} 1)$. Further additions of cationic surfactant $\left(37.8610^{-3} \mathrm{mmol} / \mathrm{L}\right.$ and $\left.188.510^{-3} \mathrm{mmol} / \mathrm{L}\right)$ reveal a dense packing of unilamellar vesicles often opened and sometimes reminiscent of facetted self-assemblies (Fig. 5d2 and 5e) (Vautrin et al. 2004). The vesicular architecture is identified from the higher electron density at the edges of structures. The diameter of the vesicles ranges from 15 to $45 \mathrm{~nm}$ whereas the thickness of the vesicles walls is in the 1.2-2.8 nm range. Spongy network structures are also found to coexist with the vesicles (e.g. Fig. 5d1). According to Zheng et al. (2000), those structures correspond to entangled threadlike micelles that form from some severely sheared vesicles during the blotting stage. When the DTAC concentration is increased to $375.210^{-3} \mathrm{mmol} / \mathrm{L}$ (Fig. 5f), irregular monodisperse structures, slightly inhomogeneous and about $16 \mathrm{~nm}$ in diameter, are observed. Those structures are 
one DTAC concentration $(33 \mathrm{mmol} / \mathrm{L}$ ) was investigated on the DTAC-rich side of the phase diagram at natural $\mathrm{pH}$ (Fig. 5g). Considering the high dilution of the SRHA suspension necessary to achieve such DTAC concentration, only a few well-formed vesicles with diameters ranging 10 to $25 \mathrm{~nm}$ were identified (Fig. $5 \mathrm{~g}$ ).

At $\mathrm{pH} 6.7$, an addition of $7.610^{-3} \mathrm{mmol} / \mathrm{L}$ of cationic surfactant to the SRHA suspension also promotes the formation of small irregular vesicular structures more complete than at $\mathrm{pH} 3.1$; the size of those vesicles ranges from 10 to $50 \mathrm{~nm}$ (Fig. 6a1). Increase of the DTAC concentration to $22610^{-3} \mathrm{mmol} / \mathrm{L}$ leads to well-defined spherical vesicles - 16 to $30 \mathrm{~nm}$ in diameter - that form multilamellar structures with ample spacing between entrapped and outer vesicles (Fig. 6b1). The wall thickness of vesicles remained in the 1.2-2.8 nm range. In both cases, some deformed vesicles are observed, thus indicating that the vesicles may either merge or separate from larger assemblies. Branched spongy networks, with budding vesicles at the higher investigated DTAC concentration, can also be found (Fig. 6a2-b2). The surfactant concentration added to reach the DTAC-rich side of the phase diagram also implies an important dilution of the SRHA suspension. At a DTAC concentration of $33 \mathrm{mmol} / \mathrm{L}$, large $(\sim$ $100 \mathrm{~nm}$ in diameter) slightly granulated globules are observed to coexist with infrequent vesicles. Such globules represent aggregates of neutralized SRHA/DTAC complexes, whereas an increase of DTAC concentration to $34.9 \mathrm{mmol} / \mathrm{L}$ lead to partially aggregated vesicles, about $20 \mathrm{~nm}$ in size (Fig. 6d). Therefore, at both investigated $\mathrm{pH}$, a sequence of structures including humic-rich vesicles, aggregated complexes, and DTAC-rich vesicles, can be observed with increasing DTAC concentration.

As illustrated in Figure 7, when a cationic surfactant with a longer alkyl chain is added to the SRHA suspension at natural $\mathrm{pH}$, i.e. CTAC $(\mathrm{C} 16)$, aggregated globules are the prevailing molecular structures. The size of globules increases with the CTAC concentration, from 12-20 $\mathrm{nm}$ in size at $3.12 \times 10^{-5} \mathrm{mmol} / \mathrm{L}$ to $20-32 \mathrm{~nm}$ at $18.7 \times 10^{-5} \mathrm{mmol} / \mathrm{L}$, reaches $30-60 \mathrm{~nm}$ at 93.6 
$\mathrm{x} 10^{-5} \mathrm{mmol} / \mathrm{L}$, and then decreasing to around $40 \mathrm{~nm}$ at $311 \times 10^{-5} \mathrm{mmol} / \mathrm{L}$. The aggregates of

325 globules are ramified at low CTAC concentration, becoming more compact as the surfactant concentration is increased, and appear to redisperse at the highest investigated concentration of CTAC.

The difference in behaviour between SRHA/DTAC and SRHA/CTAC complexes can be related to the length of the surfactant alkyl chain. In the case of CTAC, the temperature of the suspension is only slightly above the Krafft temperature of the surfactant. Upon interaction between CTAC and SRHA, the neutralization of the negatively charged functional groups of the humic structure by the positive ammonium headgroups of the surfactant increases the hydrophobicity of the resulting complex. Near the chain melting temperature of the free surfactant, the additional hydrophobic interactions between the alkyl chain and the humic complex might stiffen the CTAC chain, thus facilitating the formation of a precipitate. The presence of facetted vesicles in the SRHA/DTAC system certainly reflects the coexistence of ordered alkyl chains in the molecular structures generated with the C12 surfactant (Vautrin et al. 2004).

\section{DISCUSSION}

4.1 Complexation of SRHA with alkyltrimethylammonium cationic surfactants. Previous

studies on the interactions between humic substances and cationic surfactants were interested in two main aspects: (i) the fate of the surfactant molecule introduced in the natural environment either as an organic contaminant through wastewater discharge (Koopal et al. 2004; Ishiguro et al. 2007; Hakim and Kobayashi 2019) or as a detergent for the remediation of aquifers and contaminated soils (Harwell et al. 1999; Mao et al. 2015); (ii) the chemical structure of the humic substances, the surfactant being used as a probe of amphiphilic 
properties of humic matter or as a titrant of the total amount of carboxyl functional groups

et al. 2016). Overall, the reports concur that the binding of the cationic surfactant to the humic substance initially proceeds through strong electrostatic interactions between the carboxylic groups of humic matter and the positively charged head groups of the surfactant. This leads to the formation of a precipitate when the charge neutralization of the humic matter is achieved charge neutralization, supplementary binding of cationic surfactant to the humic/surfactant complexes occurs through cooperative hydrophobic effects. A charge reversal and a restabilization of humic/surfactant complexes can also be observed in this region (De Nobili et al. 1990; Ishiguro et al. 2007; Hakim and Kobayashi 2019). Highly surface-active complexes are formed at very low surfactant concentrations, which suggests that structural rearrangements of the humic substances may occur upon the addition of cationic surfactant (Koopal et al. 2004; Gambo and Olea 2006).

Our findings are consistent with the literature, yet they provide further precision about some key features of the complexation of humic matter with cationic surfactants. The contrasting evolution of turbidity-surfactant concentration curves, normalized to the respective solubility of surfactants, suggest that the alkyl chain length plays a significant role in the association between the cationic surfactant and SRHA for the low surfactant concentrations. Indeed, the addition of OTAC to the SRHA suspension only produces a minor increase of turbidity in comparison with that induced by CTAC, even though the electrophoretic mobility curves of resulting complexes indicate similar neutralization behaviours at low surfactant concentrations (Fig. 2-3). A likely explanation is that the order-disorder transition of surfactant alkyl chain occurs at increased temperature after interaction of surfactant with the hydrophobic moieties 
of humic matter. In the case of DTAC, the presence of vesicles implies that the alkyl chain maintains a high degree of conformational disorder upon association with SRHA. Likewise, the shorter alkyl chain of OTAC should also remain disordered. However, the C16-alkyl chain of CTAC certainly becomes ordered in the SRHA/CTAC complex as suggested by (i) the early formation of a compact precipitate (Fig.7), and (ii) the surface tension of SRHA/CTAC suspensions similar to that of pure water in the low surfactant concentration regime unlike the surface tension of SRHA/DTAC and SRHA/OTAC suspensions (Fig. 4). It is indeed peculiar that the complexes formed with the longer-chain surfactant are the less surface active at low surfactant concentrations, thus suggesting that the alkyl chain does not stick out of water under those conditions.

The minimum exhibited in the electrophoretic mobility curves of SRHA/CTAC and SRHA/DTAC complexes is also an intriguing feature. A similar trend has been reported for the Suwannee River fulvic acid/DTAC system. In that case, the minimum is interpreted as the result of a rearrangement of fulvic acid upon neutralization with the cationic surfactant (Chaaban et al. 2016). Indeed, the initial neutralization of external sites of humic matter by the cationic surfactant enhances the hydrophobicity of the complex, that then undergoes a structural rearrangement turning inside-out some previously unattainable negatively charged sites (Sieliechi et al. 2008). Our results are consistent with such interpretation, although, in the case of DTAC, the minimum in electrophoretic mobility certainly occurs at surfactant concentrations slightly lower than those investigated in this study.

Only partial neutralization of SRHA is reached with the addition of OTAC, whereas CTAC and DTAC promote a complete charge compensation of the humic matter. Using the titration data of SRHA reported by Ritchie and Perdue (2003), it can be verified that the amount of CTAC added at the point of charge compensation, i.e. $0.077 \mathrm{mmol} / \mathrm{L}$, is close to the amount of negative charges of SRHA at $\mathrm{pH} 4.5$, i.e. $0.066 \mathrm{meq} / \mathrm{L}$. This indicates that most (around 85\%) 
CTAC molecules are bound to SRHA. Similar calculations indicate the opposite situation for

DTAC where a minor amount of surfactant molecules seems to be associated with the humic matter at the point of charge neutralization at either $\mathrm{pH} 4.5$ or 6.7 . Such results are in line with the binding isotherms of dodecyl-pyridinium chloride and cetyl-pyridinium chloride to various humic acids reported by Ishiguro et al. (2007) and Yee et al. (2006).

As the neutralization of SRHA is carried out with monovalent cationic surfactants, further binding of surfactant above the point of charge compensation is necessarily driven by cooperative hydrophobic interactions either between interacting alkyl tails of the surfactant or between alkyl chains and hydrophobic moities of the humic matter. This change in surfactant binding mode and the resulting charge reversal of complexes, have been well documented in previous studies (Ishiguro et al. 2007; Hakim and Kobayashi 2019). However, the break in the surface tension curve that defines the $\mathrm{CAC}$ is also known to signal the onset of cooperative association of surfactant to the complexes in polyelectrolyte/surfactant systems (Jain et al. 2004; Bain et al. 2010). In our case, CACs of $3.6 \mathrm{mmol} / \mathrm{L}, 0.4 \mathrm{mmol} / \mathrm{L}$, and $0.022 \mathrm{mmol} / \mathrm{L}$ are obtained at $\mathrm{pH} 4.5$ for OTAC, DTAC, and CTAC, respectively; a CAC of $0.7 \mathrm{mmol} / \mathrm{L}$ is found for DTAC at pH 6.7 (Fig. 4). The CAC values determined for DTAC and CTAC are therefore much lower than the surfactant concentrations necessary for charge neutralization of SRHA. Interestingly, The CAC concentrations are in the vicinity of minima of electrophoretic mobility curves. Furthermore, even though the degree of conformational disorder of surfactant alkyl chain may vary in the SRHA/surfactant complexes, the logarithm of CACs can be related to the surfactant chain length just as $\log (\mathrm{CMC})$ of cationic surfactants (Fig. S4 in Supporting 419 information). Such dependence implies that micellization is initiated in the process of SRHA/surfactant interaction and well before charge neutralization. Therefore, after noncooperative binding of cationic surfactant to the external carboxyl groups of SRHA, the pooling of alkyl chains of bound surfactant probably triggers a rearrangement of humic matter to make 
additional negatively charged sites available for binding. A rapid calculation gives a value of

424

425

426

427

428

429

430

431

432

433

434

435

436

437

$3.2 \mathrm{~kJ} / \mathrm{mol}$ for the free energy of binding per $\mathrm{CH}_{2}$ group which is consistent with previous studies on humic substances/surfactant binding (Yee et al. 2006).

4.2 Clues to a supramolecular organization of extracted humic matter. The use of a surfactant as a probe of a given molecular structure, polymeric or self-assembly, primarily relies on the aggregation behaviour upon addition of increasing concentrations of surfactant. In the SRHA/n-alkyl trimethylammonium chloride system, both $\mathrm{pH}$ and alkyl chain length of the surfactant, i.e. charge of humic matter and strength of hydrophobic interactions, strongly influence the aggregation. If we only consider DTAC, the turbidity pattern is reminiscent of a polyelectrolyte/surfactant-like interaction at pH 4.5 (Bakshi and Sachar 2004), whereas the observation of two distinct turbidity peaks at $\mathrm{pH} 6.7$ is in line with the phase behaviour of a mixture of oppositely charged surfactants (Marques et al. 1998, 1999), i.e. implies a supramolecular structure of humic matter. Obviously, both molecular structures cannot simultaneously apply to describe the organization of SRHA.

Another key feature in identifying the organization of extracted humic matter is the nature of turbidity that results from the SRHA/surfactant interaction. At acid $\mathrm{pH}$, direct imaging using cryo-TEM evidences a sequence of structures comprising globules tentatively attributed to mixed micelles, small unilamellar humic-rich vesicles, presumably aggregated structures, and then DTAC-rich vesicles. At $\mathrm{pH}$ 6.7, an equivalent sequence of humic-rich vesicles, SRHA/DTAC aggregated structures, and DTAC-rich vesicles can be observed. Such sequences bear striking similarities with the phase behaviour of aqueous mixtures of anionic and cationic surfactants (Herrington et al. 1993; Marques et al. 1998, 1999). Indeed, mixing of oppositely charged surfactants typically leads to mixed micelles, anionic-rich vesicles, equimolar 
aggregates, cationic-rich vesicles, and mixed micelles, as a function of mixing ratio. Therefore, the sequence of molecular structures resulting from the interaction of SRHA with increasing concentrations of DTAC supports a supramolecular organization of extracted humic matter.

450 Such conclusion, reached with $1 \mathrm{~h}$ mixing time, is unlikely to be reversed by using longer 451 mixing times. The SRHA/DTAC turbidity curve at $\mathrm{pH} 4.5$ may then reflect the close vicinity 452 of the two regions of vesicles stability in the phase diagram. Moreover, an increased protonation of SRHA clearly facilitates the formation of a high number of vesicles, thus suggesting a facilitated restructuring.

Synthetic amphiphilic block copolymers have also been shown to assemble into micelles, lamellae, and a variety of complex vesicular structures including flowerlike vesicles or stacked bowls (Liu et al. 2019; Wang et al. 2019). However, in that case, the transition process from one molecular structure to another generally involves shear-induced transformations and the obtained assemblies are kinetically trapped. In our study, all the vesicles were spontaneously formed which is also a supplementary feature of aqueous mixtures of anionic and cationic surfactants (Kaler et al. 1992; Marques et al. 1999). In addition, in the case of amphiphilic block copolymers the thickness of vesicle wall is about 10 to $30 \mathrm{~nm}$, whereas less than $2.8 \mathrm{~nm}$ thick walls, i.e. less than the expected thickness of a bilayer formed from 12-carbon tail surfactants, was found for the vesicles formed in the SRHA/DTAC system.

The thinness of vesicles walls suggests that the building blocks of humic matter are of a size similar to that of surfactant molecules. Such result is consistent with previous size estimates of humic matter (Lead et al. 2000). Not knowing the amount of DTAC bound to SRHA, the geometric packing constraints associated with the formation of vesicles cannot be used to better define the size of those humic constituents. Nevertheless, estimates for the mean crosssectional surface area per SRHA/DTAC complex aSRHA/DTAC at the air/water interface can be 
471

472

473

474

475

476

477

478

479

480

481

482

483

484

485

486

487

inferred from the surface tension measurements using the Gibbs adsorption isotherm at the maximum value of $d \gamma / d \ln (\mathrm{C})$ (Eastoe et al. 1996; Gamboa and Olea 2006):

$$
a_{S R H A / D T A C}=\frac{1}{\Gamma_{\max } N_{a}}=-\frac{R T}{N_{a}} \frac{d \ln (C)}{d \gamma_{e q}}
$$

in which $\Gamma_{\max }$ is the surface excess of SRHA/DTAC complexes, $N_{a}$ Avogadro's number, R the ideal gas constant, $\mathrm{T}$ the absolute temperature, $\gamma$ the surface tension, and $\mathrm{C}$ the molar concentration of surfactant. The least-squares fits to the pre-CMC $d \gamma / \mathrm{d} \ln (\mathrm{C})$ data lead to asRHA/DTAC values of $191 \pm 32 \AA^{2}$ and $69 \pm 25 \AA^{2}$ at $\mathrm{pH} 4.5$ and at pH 6.7, respectively (The confidence intervals for the asRHA/DTAC values are obtained using a Student t-test with a significance level of 5\%). Such values compare favourably with those obtained by Gamboa and Olea (2006) in the Aldrich humic acid/alkyltrimethyl ammonium Bromide system. In mixtures of oppositely charged surfactants, previous studies have shown that the mean area per molecule of complex is slightly less than the sum of individual components cross-sectional surface areas (Rodakiewicz-Nowak 1981; Eastoe et al. 1996). Using a value of $40 \AA^{2}$ for a atAC (Weiner and Zografi 1965), asRHA should then be about $30 \AA^{2}$ at $\mathrm{pH} 7$ and $150 \AA^{2}$ at natural $\mathrm{pH}$. Those cross-sectional surface areas fall in the 30 to $190 \AA^{2}$ range reported in the literature for humic acids (Chen and Schniter 1978; Kawahigashi and Fujitake 1998; Terashima et al. 2004; Gamboa and Olea 2006; Chaaban et al. 2016). Nevertheless, it should be noted that in the pre-CMC linear region, SRHA/DRAC complexes remain slightly charged. As a result, because of electrostatic repulsion, close packing may not be reached and the mean surface area occupied by the complexes at the air/water interface is certainly slightly overestimated. In any case, such molecular area is much smaller than those typically found for polyelectrolytes (Caminati and Gabrielli 1993).

\section{CONCLUSIONS}


494 The results presented in this paper shed new light on the interaction mechanisms involved

495 between humic acid and cationic surfactants under environmentally relevant conditions. In

496 particular, we show that the hydrophobic interactions occurring between either alkyl chains of

497 bound surfactants or surfactant alkyl chains and hydrophobic moieties of humic matter, induce

498 a drastic rearrangement of the humic structure at low surfactant concentration. Those

499 hydrophobic interactions may stiffen the alkyl tails of surfactants, i.e. decrease the order-

500 disorder transition temperature of alkyl chain, which in the case of C16 chain length promotes

501 the formation of precipitates. In contrast, shorter alkyl chains remain flexible and trigger the

502 formation of small nanoscale vesicles in the case of DTAC. Cooperative hydrophobic binding

503 of surfactant molecules also concurs to the neutralization and the charge reversal of

504 humic/surfactant complexes except for the short C8-alkyl chains. The formation of vesicular

505 structures and the high surface activities of complexes formed between humic acid and DTAC,

506 offer renewed perspectives for the use of cationic surfactants in the remediation of

507 contaminated ecosystems. Indeed, because of enhanced adsorption onto negatively charged

508 soil particles and acute toxicity for microorganisms, cationic surfactants are generally not used

509 for the treatment of oil-contaminated environments (Mao et al. 2015). The possibility of

510 obtaining negatively charged nanosize vesicles from complexes of humic matter and cationic

511 surfactant would certainly improve both transport properties and environmental compatibility

512 of cationic surfactants.

513 The phase behaviour of SRHA/DTAC complexes and the spontaneous formation of nanoscale

514 unilamellar vesicles are key features of mixtures of oppositely charged surfactants. Such results

515 support the supramolecular view of humic matter and are completely in line with the 516 amphiphilic nature of humic substances (Chen and Schnitzer 1978; Guetzloff and Rice 1994;

517 von Wandruszka 2000; Klavins and Purmalis 2010). As humic substances have been shown to

518 be mixtures of heterogeneous compounds (Simpson et al. 2002; Sutton and Sposito 2005), it is 
possible that only part of the humic building blocks participate to the formation of vesicular structures, the remaining compounds not being detected by our investigation techniques. Moreover, a self-assembled humic matter suggests that part of NOM might be supramolecular but does not imply that all NOM is supramolecular. Further investigations should assess how the extraction process of humic substances could affect their organization structure.

Declaration of interest: The authors declare that they have no known competing financial interests or personal relationships that could have appeared to influence the work reported in this paper.

Data Availability Statement: The data that support this study are available on request from the corresponding author.

Acknowledgements: AAC was awarded a PhD fellowship from Azm \& Saade Association (Lebanon). AAC, BSL and CPC are grateful to Stephanie Balor and Vanessa Soldan (METI Platform - University of Toulouse III) for precious help.

\section{REFERENCES CITED}

Arnould A, Perez AA, Gaillard C, Douliez J-P, Cousin F, Santiago LG, Zemb T, Anton M, Fameau, A-L (2015). Self-assembly of myristic acid in the presence of choline hydroxide: effect of ratio and temperature. Journal of Colloid and Interface Science 445, 285-293.

Bain CD, Claesson PM, Langevin D, Meszaros R, Nylander T, Stubenrauch C, Titmuss S, von Klitzing R (2010). Complexes of surfactants with oppositely charged polymers at surfaces and in bulk. Advances in Colloid and Interface Science 155, 32-49.

Bakshi MS and Sachar S (2004). Surfactant polymer interactions between strongly interacting 
541 cationic surfactants and anionic polyelectrolytes from conductivity and turbidity

542 measurements. Colloid and Polymer Science 282, 993-999.

543 Baveye PC and Wander M (2019). The (Bio)Chemistry of soil humus and humic substances:

544 Why is the "New View" still considered novel after more than 80 years ?". Frontiers in

545 Environmental Science 7:27. doi: 10.3389/fenvs.2019.00027

546 Burdon J (2001). Are the traditional concepts of the structures of humic substances realistic?

547 Soil Science 166, 752-769.

548 Cameron RS, Thornton BK, Swift RS, Posner AM (1972). Molecular weight and shape of 549 humic acid from sedimentation and diffusion measurements on fractionated extracts. Journal 550 of Soil Science 23(4), 394-408.

551 Caminati G, and Gabrielli G (1993). Polystyrene sulfonate adsorption at water-graphon and 552 water-air interfaces. Colloids and Surfaces A: Physicochemical Engineering Aspects 70, 1-14.

553 Carter CW and Suffet IH (1982). Binding of DDT to dissolved humic materials. Environmental 554 Science and Technololgy 16(11), 735-740.

555 Cases JM and Villieras F (1992). Thermodynamic model of ionic and non-ionic surfactant 556 adsorption abstraction on heterogeneous surfaces. Langmuir 8(5), 1251-1264.

557 Chaaban AA, Lartiges B, Kazpard V, Plisson-Chastang C, Michot L, Bihannic I, Caillet C, 558 Prelot B (2016). Probing the organization of fulvic acid using a cationic surfactant. Colloids 559 and Surfaces A: Physicochemical Engineering Aspects 504, 252-259.

560 Chen, Y., and Schnitzer, M., 1978. Surface-Tension of Aqueous-Solutions of Soil Humic 561 Substances. Soil Sci. 125, 7-15. 
562 Chilom G and Rice JA (2009). Structural organization of humic acid in the solid state. 563 Langmuir 25(16), 9012-9015.

564 Chilom G, Bruns AS, Rice JA (2009). Aggregation of humic acid in solution: Contributions of 565 different fractions. Organic Geochemistry 40, 455-460.

566 Chilom G, Baglieri A, Johnson-Edler CA, Rice JA (2013). Hierarchical self-assembling 567 properties of natural organic matter's components. Organic Geochemistry 57, 119-126.

De Nobili M, Contin M, Leita L (1989). Investigation of the interactions between humic 569 substances and a cationic detergent (Cetiltrimethylammonium Bromide). Science of the Total Environment 81/82, 635-642.

De Nobili M, Contin M, Leita L (1990). Alternative method for carboxyl group determination in humic substances. Canadian Journal of Soil Science 70, 531-536.

573 Duval JFL, Wilkinson KJ, van Leeuwen HP, Buffle J (2005). Humic substances are soft and 574 permeable: evidence from their electrophoretic mobilities. Environmental Science \& 575 Technology 39, 6435-6445.

576 Eastoe J, Rogueda P, Shariatmadari D, Heenan R (1996). Micelles of asymmetric chain 577 catanionic surfactants. Colloids and Surfaces A: Physicochemical Engineering Aspects 117, $578 \quad 215-225$.

579 Engebretson RR and von Wandruszka R (1997). The effect of molecular size on humic acid 580 associations. Organic Geochemistry 26, 759-767.

581 Gamboa C and Olea AF (2006). Association of cationic surfactants to humic acid. Effect on 582 the surface activity. Colloids and Surfaces A: Physicochemical Engineering Aspects 278, 241583245. 
584 Gerke J (2018). Concepts and misconceptions of humic substances as the stable part of soil 585 organic matter: a review. Agronomy 8,76. doi:10.3390/agronomy8050076.

586 Guetzloff T and Rice J (1994). Does Humic-Acid Form a Micelle. Science of the Total 587 Environment 152, 31-35.

588 Harwell JH, Sabatini DA, and Knox RC (1999). Surfactants for ground water remediation. 589 Colloids and Surfaces Physicochemical Engineering Aspects 151, 255-268.

590 Hayes MHB, MacCarthy P, Malcolm RL, Swift RS (1989). The Search for Structure: Setting 591 the Scene. (In: Humic Substances II: In Search of Structure. MHB Hayes, P MacCarthy, RL 592 Malcolm, RS Swift (eds), Wiley, Chichester, New York, 3-32).

593 Herrington KL, Kaler EW, Miller DD, Zasadzinski JA, Chiruvolu S (1993). Phase behavior of 594 aqueous mixtures of Dodecyltrimethylammonium bromide (DTAB) and sodium dodecyl 595 sulfate (SDS). Journal of Physical Chemistry 97, 13792-13802.

596 Hosse M and Wilkinson KJ (2001). Determination of electrophoretic mobilities and 597 hydrodynamic radii of three humic substances as a function of $\mathrm{pH}$ and ionic strength, 598 Environmental Science \& Technology 35, 4301-4306.

599 Ishiguro M, Tan W, Koopal LK (2007). Binding of cationic surfactants to humic substances. 600 Colloids and Surfaces A: Physicochemical Engineering Aspects 306, 29-39.

601 Israelachvili JN, Mitchell DJ, Ninham BW (1976). Theory of self-assembly of hydrocarbon 602 amphiphiles into micelles and vesicles. Journal of Chemical Society Faraday Transactions $6032(72), 1525-1568$.

604 Jain N, Trabelsi S, Guillot S, McLoughlin D, Langevin D, Letellier P, Turmine M (2004). 605 Langmuir 20, 8496-8503. 
607 anionic and cationic surfactants. Journal of Physical Chemistry 96, 6698-6707.

608 Kawahigashi M and Fujitake N (1998). Surface-active properties of particle size fractions in 609 two humic acids. Journal of Soil Science and Plant Nutrition 44(4), 497-505.

610 Kerner M, Hohenberg H, Siegmund E, Reckermann M, Spitzy A (2003). Self-organization of 611 dissolved organic matter to micelle-like microparticles in river water. Nature 422, 150-154. 612 doi:10.1038/nature01469

613 Kelleher B and Simpson AJ (2006). Humic substances in soils: are they really chemically 614 distinct ? Environmental Science \& Technology 40, 4605-4611.

615 Khan N and Brettmann B (2019). Intermolecular interactions in polyelectrolyte and surfactant 616 complexes in solution. Polymers 11, 51. doi:10.3390/polym11010051

617 Klavins M and Purmalis O (2010). Humic substances as surfactants. Environmental Chemistry 618 Letters 8, 349-354.

619 Koopal LK, Goloub TP, Davis TA (2004). Binding of ionic surfactants to purified humic 620 acid. Journal of Colloid and Interface Science 275, 360-367.

621 Laschewsky A, Wattebled L, Aroçarena M, Habib-Jiwan J-L, Rakotoaly RH (2005). Synthesis 622 and properties of cationic oligomeric surfactants. Langmuir 21, 7170-7179.

623 Lead JR, Wilkinson KJ, Starchev K, Canonica S, Buffle J (2000). Determination of diffusion 624 coefficients of humic substances by fluorescence correlation spectroscopy: role of solution 625 conditions. Environmental Science \& Technology 34, 1365-1369. 

and blotless cryo-TEM imaging: a new method for probing early evolution of nanostructures.

628 Langmuir 28, 4043-4046.

629 Lehmann J and Kleber M (2015). The contentious nature of soil organic matter. Nature 528, 630 60-68. doi: 10.1038/nature16069.

631 Lindblom G and Lindman B (1973). Interaction between halide ions and amphiphilic organic 632 cations in aqueous solutions studied by nuclear quadrupole relaxation. Journal of Physical 633 Chemistry 77, 2531-2537.

634 Liu W, Chen H, Pan D, Ji X (2019). Electrostatic interaction mediates the formation of 635 vesicular structures from coassembly of PS-b-PAA with quantum dots. Langmuir 35 (38), 636 12501-12508.

Mao X, Jiang R, Xiao W, Yu J (2015). Use of surfactants for the remediation of contaminated soils: a review. Journal of Hazardous Materials 285, 419-435.

Manohar C and Narayanan J (2012). Average packing factor approach for designing micelles, 640 vesicles and gel phases in mixed surfactant systems. Colloids Surfaces A: Physicochemistry 641 Engineering Aspects 403, 129-132.

642 Marques EF, Regev O, Khan A, Miguel MG, Lindman B (1998). Vesicle formation and general 643 phase behavior in the catanionic mixture SDS-DDAB-Water. The anionic-rich side. Journal of 644 Physical Chemistry B 102, 6746-6758.

645 Marques EF, Regev O, Khan A, Miguel MG, Lindman B (1999). Vesicle formation and general 646 phase behavior in the catanionic mixture SDS-DDAB-Water. The cationic-rich side. Journal 647 of Physical Chemistry B 103, 8353-8363. 
Martinez-Balbuena L, Arteaga-Jimenez A, Hernandez-Zapata E, Marquez-Beltran C (2017).

649

650

651

652

653

654

655

656

657

658

659

660

661

662

663

664

665

666

667

668

669

Applicability of the Gibbs adsorption isotherm to the analysis of experimental surface-tension data for ionic and nonionic surfactants. Advances in Colloid and Interface Science 247, 178184.

Olk DC, Bloom PR, Perdue EM, McKnight DM, Chen Y, Farenhorst A, Senesi N, Chin Y.P., Schmitt-Koplin P, Hertkorn N, Harir M (2019). Environmental and agricultural relevance of humic fractions extracted by alkali from soils and natural waters. Journal of Environmental Quality 48, 217-232. doi:10.2134/jeq2019.02.0041

Perger TM and Bester-Rogac M (2007). Thermodynamics of micelle formation of alkyltrimethylammonium chlorides from high performance electric conductivity measurements. Journal of Colloid and Interface Science 313, 288-295.

Piccolo A (2001). The supramolecular structure of humic substances. Soil Science 166(11) $810-832$.

Piccolo A and Conte P (1999). Conformational arrangement of dissolved humic substances. Influence of solution composition on association of humic molecules. Environmental Science \& Technology 33, 1682-1690.

Ritchie JD and Perdue EM (2003). Proton-binding study of standard and reference fulvic acids, humic acids, and natural organic matter. Geochimica and Cosmochimica Acta 67(1), 85-96.

Rodakiewicz-Nowak J (1981). Surface characteristics of some anionic, cationic, and anioniccationic surfactants. Journal of Colloid and Interface Science 84(2), 532-535.

Shang C and Rice JA (2007). Investigation of humate-cetyltrimethylammonium complexes by small-angle X-ray scattering. Journal of Colloid and Interface Science 305, 57-61. 
671 de la Caillerie J-B, Barres O, Kamga R, Levitz P, Michot LJ (2008). Changes in humic acid 672 conformation during coagulation with ferric chloride: Implications for drinking water 673 treatment. Water Research 42(8-9), 2111-2123.

674 Simpson AJ, Kingery WL, Hayes MHB, Spraul M, Humpfer E, Dvortsak P, Kerssebaum R, 675 Godejohann M, Hofmann M (2002). Molecular structures and associations of humic substances 676 in the terrestrial environment. Naturwissenschaften 89(2), 84-88.

677 Smejkalova D and Piccolo A (2008). Aggregation and Disaggregation of humic 678 supramolecular assemblies by NMR Diffusion Ordered Spectroscopy (DOSY-NMR). 679 Environmental Science \& Technology 42, 699-706.

680 Stevenson FJ (1994). Humus Chemistry. Genesis, Composition, Reactions. John Wiley: New 681 York, NY, USA.

682 Sutton R and Sposito G (2005). Molecular structure in soil humic substances: the new view. 683 Environmental Science \& Technology 39, 9009-9015.

684 Swift RS (1999). Macromolecular properties of soil humic substances: fact, fiction, and 685 opinion. Soil Science 164(11) 790-802.

Tan CH, Huang ZJ, Huang XG (2010). Rapid determination of surfactant critical micelle 687 concentration in aqueous solutions using fiber-optic refractive index sensing. Analytical 688 Biochemistry 401, 144-147.

689 Terashima M, Fukushima M, Tanaka S (2004). Influence of $\mathrm{pH}$ on the surface activity of humic 690 acid: micelle-like aggregate formation and interfacial adsorption. Colloids and Surfaces A: 691 Physicochemical Engineering Aspects 247, 77-83. 
692 Thurman EM, Malcolm RL (1981). Preparative isolation of aquatic humic substances.

693 Environmental Science \& Technology 15, 463-466.

694 Tombacz E, Varga K, Szanto F (1988). An X-ray diffraction study of alkylammonium humate 695 complexes. Colloid and Polymer Science 266, 734-738.

696 Vautrin C, Zemb T, Schneider M, Tanaka M (2004). Balance of pH and ionic strength 697 influences on chain melting transition in catanionic vesicles. Journal of Physical Chemistry B 698 108, 7986-7991.

von Wandruszka R (2000). Humic acids: Their detergent qualities and potential uses in 700 pollution remediation. Geochemical Transactions 1, 10-15.

Wang X, Liu S, Cao S, Han F, Wang H, Chen H (2019). Tandem self-assembly of block copolymer: from vesicles to stacked bowls. Macromolecules 52, 6698-6703.

703

Weiner ND and Zografi G (1965). Interfacial properties of antimicrobial long-chain quaternary ammonium salts I. Soluble films at the air water interface. Journal of Pharmaceutical Sciences 54(3), 436-442.

706

Wells MJM and Stretz HA (2019). Supramolecular architectures of natural organic matter.

Science of the Total Environment 671, 1125-1133. doi.org/10.1016/j.scitotenv.2019.03.406.

Wershaw RL (1999). Molecular aggregation of humic substances. Soil Science 164, 803-813.

Yee MM, Miyajima T, Takisawa N (2006). Evaluation of amphiphilic properties of fulvic acid and humic acid by alkylpyridinium binding study. Colloids and Surfaces A: Physicochemical

711 Engineering Aspects 272, 182-188.

712 Zheng Y, Lin Z, Zakin JL, Talmon Y, Davis HT, Scriven LE (2000). Cryo-TEM imaging the 713 flow-induced transition from vesicles to threadlike micelles. Journal of Physical Chemistry B 
714 104, 5263-5271.

715

716

717

718

719

720

721 